\title{
Para o princípio do 'cuidado de si' na práxis musical do pesquisador: a filosofia de uma metodologia
}

Toward the principle of self or care in the musical praxis by researcher: the philosophy of a methodology

por Daniel Vieira

RESUMO

0 presente trabalho apresenta o princípio filosófico do 'cuidado de si' integrado à condição humana própria da natureza do ato de performance como ato estético. 0 'cuidado de si', como caracterizado por Foucault (2010), é um modo de encarar a vida, numa atitude para consigo a partir da conversão do olhar do outro sobre si. 0 autor vale-se da metodologia inerente a este princípio filosófico aplicando-o à prática musical e esse olhar permite sua projeção para a prática de pesquisa em Práticas Interpretativas. Enfim, uma série de procedimentos metodológicos, quer para a prática musical, como para a prática de pesquisa, são sugeridos, de modo a permitir uma valorização da práxis profissional musical do próprio pesquisador.

Palavras-chave 'cuidado de si'; processos de subjetivação; práxis musical; pesquisa em música; filosofia da performance

\section{ABSTRACT}

This paper presents the philosophical principle of self-care integrated into the condition of human nature as an aesthetic action. 'Self-care', as characterized by Foucault (2010), is a way of looking at life, an attitude towards yourself from the conversion of someone else's look of yourself. The author uses the methodology inherent in this philosophical principle by applying it to musical practice and this look allows its projection for research in musical performance. Finally, a series of methodological procedures, both for the practice of music, as well as for research practice, are suggested in order to allow for a valorization of the researcher's . professional musical practice.

Keywords 'self-care'; subjectivation processes; musical praxis; music research; performance philosophy 


\section{Introdução}

Inicio este polígrafo posicionando-me como músico que procura conscientemente a sua realidade no fazer diário da performance musical. Acrescento, entremeios, a ideia de que a música, como arte, deve favorecer à possibilidade de reencontro entre 0 ato realizado e vivenciado com o humano que se faz presente no momento do ato estético. Refiro-me, em recente publicação', a esse reencontro entre a condição humana com o ato artístico como encantamento. Dessa ideia de encantamento, cito dois aspectos que se tornam urgentes para mim: o primeiro é referente à adoção incondicional de um princípio estético, o segundo é a progressão paulatina na concepção de que o reencontro do eu, no ato artístico, como no ato humano, é o caminho para a fruição da própria condição humana a partir da música hoje e sempre. 0 próprio reencontro do intérprete musical, como performer, seria qual o impacto criado se, de alguma maneira, fosse invertida a ordem dessa experiência na busca de sua própria fruição.

Ora, tal posicionamento delineia uma novidade para a própria concepção de uma obra musical, pois buscas ontológicas e universais abririam espaço para o reconhecimento do êthos ${ }^{2}$, ou mesmo de um páthos ${ }^{3}$, naturalmente humano, e esse passaria a conduzir o interesse à necessidade da música como meio de reencontro. Porém, o estado de encantamento próprio à natureza estética da música valorizaria, inclusive, 0 ato da performance como ato estético em si - de si para si.

\section{Prolegômenos: 0 aspecto humano da performance musical e o princípio do 'cuidado de si'}

0 aspecto humano aparente no ato da performance musical conduz linearmente para a filosofia, que, como argumentado por Derrida ${ }^{4}$, é determinada como reflexão poética. A esse respeito, é possível valorizar alguns questionamentos levantados por Michel Foucault, quando ele diz:

\footnotetext{
1 (Ver: VIEIRA, 2011).

2 Palavra de origem grega cujo significado abarca o conjunto das características morais, afetivas, sociais e comportamentais próprias do ser humano. Na arte e na estética, o êthos é entendido como uma constância emocional. 0 Dicionário Abbagnano a define como tudo o que é próprio do caráter humano (ABBAGMANO, 1998, p. 116).
}

3 Expressão grega entendida como algo que desperta o sentimento de piedade, paixão ou algo que possui a capacidade de comover. Na tradição filosófica, seu conceito designa tudo o que acontece de novo. Na arte e na estética é associado ao dinamismo emocional. Com a mesma condição própria da humanidade, significa o oposto de êthos (ABBAGMANO, 1998, p. 117).

4 "Pois a filosofia foi determinada na sua história como reflexão da inauguração poética" (DERRIDA, 2009, p. 38). 
De que valeria a obstinação do saber se [a filosofia] apenas garantisse a aquisição de conhecimentos, e não, de uma certa maneira e tanto quanto possivel, o extravio daquele que conhece? (...) [E ainda, outra questão:] "Mas o que é, então, a filosofia hoje - quero dizer, a atividade filosófica - se não o trabalho crítico do pensamento sobre si mesmo?" (FOUCAULT, 2010, p. 196-197).

Com isso, uma nova consideração do eu, do humano, como condicionador dessa experiência estética, torna-se iminente como problematização do sujeito. Uma estética de si $^{5}$, hermenêutica da vida, vem a ser a ação direcionadora para o reencontro com o seu próprio valor ético, de forma a considerar "sua vida uma obra que seja portadora de certos valores estéticos e que corresponda a certos critérios de estilo" (FOUCAULT, 2010, p. 199). 0 entendimento dessa experiência encontra-se no simples ato de vivê-la. 0 desafio, nesse caso, como atitude estética requerida na experiência da performance musical, passa a ser a conversão da condição hermenêutica para a própria existência do sujeito, mesmo do indivíduo ato realizado.

A constituição do sujeito humano, de como o homem fala de si próprio, pode funcionar como um dispositivo que o constitui como objeto de sua própria ciência. Se a música, neste contexto, faz o músico, então sem a existência de um discurso para essa música e esse músico, não haveria um sujeito humano subjetivado presente na ação do fazer música. À parte todas as condições de poder-saber, o sujeito não se torna soberano, e sim produto de seu tempo, reagindo contra os demais objetos graças ao pensamento. Através do pensamento sua subjetividade elimina a metafísica que extrai a falácia da soberania do sujeito constituído.

Subjetivação $0^{6}$ e estetização, para Foucault, caracterizam um processo de socialização que não constitui o sujeito numa "perfeita obra de arte", mas conduz a iniciativa de uma "transformação de si por si próprio" (FOUCAULT, 2010b). A fim de construir um escopo teórico concernente ao sujeito envolvido numa atitude estética, num processo situacional de performance, centralizo o foco de discussão para a minha experiência e reflexão7 como sujeito/indivíduo de atitude estética, sob um olhar amparado no curso proferido por Michel Foucault entre 1981-1982 no Collège de France, intitulado "A Hermenêutica do Sujeito", que é diretamente vinculado ao

5 Adiante será discorrido sobre a ideia da estética da existência, baseado no mesmo conceito e princípio do 'cuidado de si'.

6 Note-se que a expressão subjetivação difere de subjetividade, ampliando o sentido desta, de maneira a considerar uma consciência de si próprio, a partir do olhar da alteridade. Adiante isso será expandido no texto.

7 Este texto é um excerto de minha Tese de Doutorado, intitulada: 'Boisinhos' e 'Lobosinhos' de Heitor Villa-Lobos: o cuidado de si no processo de performance como crítica para a constituição de um sujeito de atitude estética (VIEIRA, 2012). Nesse trabalho, tomando a mim como sujeito de atitude estética e sujeito de pesquisa, amparado pelo princípio do 'cuidado de si', desenvolvo um metodologia de pesquisa voltada para a ascese de minha própria ação musical. 
princípio do 'cuidado de si'8. 0 'cuidado de si' apresenta um conjunto de procedimentos que atuam progressivamente sobre o eu. Pensar nesses procedimentos como possibilidade de estetização sublinha a espontaneidade que atua tal qual o sentido da subjetivação. Paul Veyne (2011) esclarece:

Um sujeito que se estetiza livremente, ativamente, por práticas de si, é ainda filho de seu tempo: essas práticas não são "algo que o próprio indivíduo inventa, são esquemas que ele encontra em sua cultura" (VEYNE, 2011, p. 182. Aspas no original).

0 'cuidado de si' configura certo modo de encarar a vida, de estar no mundo, de praticar ações, de ter relações com o outro - é uma atitude para consigo, para com os outros, para com o mundo. "0 cuidado de si implica uma certa maneira de estar atento ao que se pensa e ao que se passa no pensamento" (FOUCAULT, 2010, p. 12). Designa algumas ações que são exercidas de si para consigo, ações pelas quais nos assumimos, modificamos, transformamos e nos transfiguramos, por exemplo, técnicas de meditação, memoração do passado, exame de consciência, verificação das representações, entre outras.

Foucault (2010) propõe que a admissão da transformação do si em sujeito de si, como um ato filosófico/espiritual, constitui-se num ato de conhecimento e somente através desse conhecimento é possível acessar a verdade, mesmo a verdade de si. Tal constituição é equiparada a um ato hermenêutico, uma hermenêutica de si. A atitude estética, a partir da constituição do sujeito, é decorrente dessa ação de cuidado "hermenêutico" de si.

0 'cuidado de si', nesse sentido, ocupar-se-á sempre consigo enquanto se é sujeito principal de suas relações, ou seja, sujeito de relações com o outro, sujeito de comportamentos e de atitudes em geral e da relação consigo mesmo. Por mais paradoxal que possa parecer, visto que a relação com o outro é sempre máxima, o 'cuidado de si' visa um conhecimento de si a ponto de se desdobrar sobre si, desvinculando-se de todos os acontecimentos exteriores a fim de buscar tal conhecimento.

Para ocupar-se consigo é preciso conhecer-se a si mesmo. Para conhecer-se é preciso olhar-se em um elemento que seja igual a si: olhar-se em num elemento

8 A partir da conceituação das expressões Epiméleia heautû ('cuidado de si') e o gnôthi seautón (conhece-te a ti mesmo), ambos identificados na tradição platônica, Foucault (2010) esclarece que a noção de 'cuidado de si' percorre toda a filosofia antiga, sendo encontrada também no início do cristianismo, e até certo ponto, na noção da espiritualidade de forma que a expressão Epiméleia heautû passou a abarcar o gnôthi seautón. As expressões: "ocupar-se consigo mesmo", "ter cuidados consigo", "retirar-se em si mesmo", "permanecer em companhia de si mesmo", tecnologia de si", "técnicas de si", "estética de si", entre outras, ao longo da história, carregam o mesmo sentido do 'cuidado de si', de maneira que a partir da injunção "ocupar-se consigo mesmo", constituíram as mais austeras, rigorosas e restritivas morais que o ocidente conheceu (FOUCAULT, 2010, p. 157). Moral, em seu sentido filosófico, discorre acerca dos atos humanos, bons costumes e deveres do homem em sociedade e perante os de sua classe. Em acréscimo, o Dicionário Abbagnano menciona que a palavra moral, utilizada como adjetivo, admite um sentido genérico como algo "espiritual" ou pertinente ao espírito (Ver: Moral, in: ABBAGNANO, 1998, p. 682). 
que traduza o princípio do saber e do conhecimento. Esse princípio de saber e de conhecimento, numa acepção próprio-musical, considero como o reconhecimento, a busca e a intervenção da tradição. Portanto, é preciso olhar a tradição, e nessa tradição reconhecer a si mesmo.

No cuidado exercido nessa ação de subjetivar a si mesmo no ato do 'cuidado de si' tem-se uma estrutura complexa, nunca dialética, como menciona Veyne (2011), na qual o objeto de cuidado é o eu, deveras, mas a finalidade é outra: sua ação com o outro. Nesse caso, a finalidade é a própria atividade estética, dotada do agora, ou seja, a própria performance musical. Essa preocupação apresenta algumas consequências para a maturidade como formação para a vida, além de gerar uma autoinstrução. Portanto, o 'cuidado de si' reverte inteiramente o sistema de valores veiculados nos relacionamentos constituídos entre professor/aluno, por exemplo. Porém, "uma elaboração de si como objeto de saber e de conhecimentos possíveis" (FOUCAULT, 2010, p. 109) necessita, constantemente, da busca consciente da ação, e mesmo influência constante do outro, naturalmente, como elemento par de coerências na tradição vivida. Quando penso em tradição não excluo a própria condição de existência humana, sua cultura: escolas de interpretação, reconhecimento de a priori históricos, como Veyne (2011) o conceitua, de modo que o outro é indispensável nessa prática de si.

Num sentido de atitude estética a prática de si, o 'cuidado de si', conduz à catarse: a alma descobrindo sua identidade, o que ela é, sabe ou sempre soube. Descobre, desse modo, a um só tempo, o seu ser e o seu saber. Descobre, em si, a contemplação de verdades que permitem fundar a si próprio, com toda a justiça. Favorece ao desprendimento pouco a pouco sem que a ação do outro constitua o fim último e indicador na valorização do próprio eu em seu cuidado. A meta do 'cuidado de si' é o eu, o seu reconhecimento, e esse assume uma proporção de comportamento estético diante da vida. Nesse sentido e nesse contexto, diante da própria vida se assume uma atitude estética.

As responsabilidades advindas da atitude de 'cuidado de si' geram, processualmente, uma conversão de si em si próprio. Tal conversão trata-se de uma liberação em relação àquilo que não se domina. Essa liberação não ocorre em relação ao corpo, mas além do corpo, consumada e adequada de si para consigo, em direção de si. 0 conhecimento de si, nesse sentido, desempenha um papel fundamental, pois se conhecerá justamente o que constitui o seu próprio elemento essencial, fundamental para o crescimento e aprimoramento nesse 'cuidado de si'. Essa conversão pode ter a forma específica de atos que visam à atitude estética proporcionando uma autossubjetivação conjugada a uma autorreflexão.

Foucault (2010) propõe que para se atingir tal estado, autosubjetivado de autorreflexão, convertido em si, dentro dessa busca por si mesmo, são necessárias uma série de exercícios de memória - os hupomnêmata. Esses exercícios, essas técnicas, funcionam como arquivos com informações práticas e teóricas de si, sobre si, para si, mantidos pela escrita de si, fundamentados como exercícios de concentração e memoração, meditação e treino - arquivos de práticas. 
Tais práticas parecem convergir, na prática musical, para a transformação do performer como sujeito de si durante 0 ato de performance. As técnicas de si, o 'cuidado de si' e o conhecimento de si permitem um olhar do alto sobre si, um afastamento do eu sobre e sob o eu executado através do retorno aos seus arquivos.

0 'cuidado de si' e o conhecimento de si são estabelecidos sobre alguns pontos fundamentais: primeiro - não se constitui em individualidade sozinho. Tal solitude apenas contribuiria para uma ignorância inerte a sua própria natureza. Um segundo aspecto pode ser delineado num modelo platônico referente ao "conhecer-se a si mesmo": apreender sua própria alma, em termos de relacionar, unificar pensamento e corpo. Nesse sentido, os exercícios de memória - os hupomnêmata - atuam positivamente na constituição do eu. Foucault (2010) diz que na reminiscência platônica encontram-se reunidos e aglutinados, num único movimento de alma, o conhecimento de si e da verdade sobre si, 'cuidado de si' e retorno ao seu próprio ser, levando esse ser a sua própria constituição.

Após a exposição dessa forma de problematizar a natureza do performer como sujeito de atitude estética é possível compreendê-la como ligada a um conjunto de importantes práticas que permeiam atividades empíricas permanecendo no tempo como "artes da existência". Ademais, as práticas envolvidas no processo de constituição de si devem ser entendidas como práticas racionais e voluntárias que apenas determinam para si algumas regras na busca de uma transformação de si em seu ser singular e fazer com que tais práticas de performance musical sejam portadoras de valores estéticos correspondentes àqueles rezados pela própria tradição de performance musical na cultura ocidental.

A busca por uma hermenêutica do sujeito procura entender como o ser humano entra nos jogos de verdade, considerando as ciências ou um modelo científico, ou naturalmente na vida 'cotidiana' do ser humano. A prática de performance musical é dotada de uma dissimulada naturalidade que obscurece o próprio ser ali presente - o músico performer - no agora da interpretação musical. Ao tomar-se como aporte metodológico um provável círculo hermenêutico de si para si, busca-se verificar o êthos presente no ato estético da performance musical, desvelando a natureza do ser ali presente, a ponto de concebê-la como atividade estética por sua própria natureza, a fim de constituir a si como seu sujeito.

A hermenêutica de si, o 'cuidado de si' e o conhecimento de si nada mais são do que uma movimentação em direção ao próprio conhecimento de si para si, como autoconhecimento a partir de um movimento de autorreflexão sobre sua própria atitude estética tornando cada ato de performance como uma experiência própria de si.

Há momentos na vida em que a questão de saber se é possível pensar de forma diferente da que se pensa e perceber de forma diferente da que se vê é indispensável para continuar a ver ou a refletir (FOUCAULT, 2010b, p. 197).

Qual a função de uma preocupação com o sujeito estético de uma performance musical? Por que procurar constituí-lo? Por que procurar conhecê-lo? Pensar em uma 
atitude estética, trata-se, em suma, do entendimento que o sujeito da performance musical, ou seja, o músico, tem da experiência de si mesmo em jogo com a música que se relaciona consigo mesmo. Isso decorre, inclusive, da maneira que sua interação se processa com seus a priori históricos. Tais a priori são concebidos como meios de relação consigo próprio e também de relacionamento com o outro, num processo de conhecimento de si, através da conversão do olhar do outro sobre si, numa possibilidade de aceitação e aprimoramento.

As técnicas de si problematizam o sujeito, tornando-o sujeito estético, constituído em si mesmo. Numa situação artística, como é o caso da performance musical, a compreensão de si e o seu autoconhecimento são formas de se atingir um grande aprimoramento. Por meio do 'cuidado de si' o autoconhecimento é atingido.

As circunstâncias para o 'cuidado de si' - a coordenação de hierarquias em seus relacionamentos, saber quem é quem e posicionar-se, honestamente, nesse meio, parecem ser condição básica; de modo que impor-se uma conduta precisa e regrada, baseada num conjunto de noções, conceitos e teorias, e torná-la como sua regra de vida, pode requerer esforços e sacrifícios - configura um caráter cotidiano que por si só é válido como condição de natureza humana. Ritos de purificação, técnicas de concentração, desligamentos de si e práticas de resistência são enquadrados entre os esforços e sacrifícios que se fazem necessários para chegar até o conhecimento de si, como meios de autoinstrução e autorreflexão. Contudo, o crescimento, o aprimoramento do eu pelo eu, sua constituição propriamente dita, só se atinge se, a partir daí, souber converter-se em si próprio, saber extrair da sua subjetividade, atingida a partir da ação do outro e sua influência sobre 0 eu, mas necessitando ser objetivada. Essa reciprocidade entre subjetivação e objetivação talvez seja a torção mais radical em todo esse movimento de ascese ${ }^{9}$ do eu sobre o si mesmo, daí a urgência da ação do outro, gerando o processo interacional. Constituir-se como sujeito estético, em um ato estético que requer a temporalidade do agora, é tarefa de uma vida, e essa vida condicionada à sua própria subjetividade objetivada.

Desse modo, o aprimoramento desejado torna-se a estética própria de sua existência: o desenvolvimento do autoconhecimento como humano uma vez que o próprio agente da atividade artística, como agente de atividade estética, é ele próprio um ser humano. Tal assunção, mesmo parecendo ser unívoca, constituída a partir do 'cuidado de si' nunca será unilateral ou de alguma maneira pobre de fruição, criação e reflexão. A participação do outro nessa constituição permite a plenitude de relacionamento social quer por meio da troca de experiências, como pela construção e mediação de linguagens - seus discursos.

90 Dicionário de Filosofia Abbagnano define Ascese propriamente como um exercício e informa que, na origem, tal expressão indicou o treinamento dos atletas e as suas regras de vida. Com os pitagóricos, os cínicos e os estóicos, a palavra começou a ser aplicada à vida moral na medida em que a realização da virtude implica na limitação dos desejos e renúncia, em busca pela mortificação da carne e uma purgação do corpo (ABBAGNANO, 1998, p. 82). Assim, com o 'cuidado de $\mathrm{si}^{\prime}$, ascese caracteriza-se pela possibilidade de aprimoramento da alma que visa um domínio sobre si para depois ampliar-se sobre os outros dentro do grupo a que se pertence. 
Os relacionamentos entre êthos e páthos vivenciados conscientemente por meio do 'cuidado de si', na constituição de seus arquivos, são todos condicionais nesse fazer estético, e por isso $\operatorname{complexos}^{10}$, não dialéticos: arte de humanos - vivenciada e apreciada por humanos. 0 aprimoramento decorrente dessa subjetivação do eu é evidenciado na interpretação que se propõe, como ato performático de si, tornando esse sujeito em sujeito estético, a partir da sua constituição com a participação do outro de forma ativa. As práticas de si, oriundas do 'cuidado de si' e do conhecimento de si, correspondem a exercícios de conduta precisa e regrada: esforços e sacrifícios para atingir-se a natureza exposta. Ao converter-se sobre si, as práticas de escrita de si sobre si, em variadas categorias, permitem a excelência nessa atividade de tomar a si como sujeito de seu próprio ato estético a ser vivido e presentificado como aperfeiçoamento da própria concepção, quer artística quanto pedagógica, da condição de natureza humana apresentada na música.

De certo modo, a questão da constituição de si, do 'cuidado de si', como exposta, é relacionada à beleza da própria vida - a própria estética da existência ou estética de si, tornando-se objeto de problematização incontornável ao objetivar a constituição de si como sujeito de performance. Uma primeira interação surge aí na preocupação de que nunca o interesse da estética da existência, como um aspecto do 'cuidado de si', propõe a cada um cuidar apenas de seu mundo pessoal sem o vínculo com as alteridades. Mesmo que o seu relacionamento, nessa linha de condução do debate, seja realizado por meio da linguagem de interação entre os alteres envolvidos, a constituição é empírica, isto é, um movimento de ascese é proveniente desse inter-relacionamento entre pares de maneira que a ação, ou seja, a prática musical vem a ser mediada por tais alteres.

Decididamente a adoção do 'cuidado de si' como meio do indivíduo fabricar a si próprio, utilizando uma cuidadosa e criteriosa reflexão sobre o seu próprio tempo (presente) numa luta constante à sua própria constituição, libertária de qualquer ranço de origem dialética ou de natureza 'estruturalista', valoriza a condição humana do ato estético da performance musical. A visão para o si é ampliada pelo seu próprio contexto vivido e considerado.

\section{0 performer e seus hupomnêmata: a constituição de seus arquivos ou o estabelecimento de sua metodologia}

A pesquisa em Práticas Interpretativas no Brasil, em geral, tem vivido uma época de transição e vislumbrado um novo paradigma que, como Boaventura de Souza Santos sugere para o campo das humanidades, vem assinalando para uma ciência pós-moderna (SANTOS, 2002). Tal paradigma corrobora com o fato que acompanha toda e qualquer

10 Ver, por exemplo: MORIN, 2003. 
pesquisa nessa área: a produção de conhecimento que, de alguma maneira, auxiliará o performer em sua práxis, seja ela tocar ou ensinar alguém a tocar (BARRENECHEA, 2003; AQUINO, 2003).

A fixação de uma determinada obra no repertório e o seu aprimoramento constante, o condicionamento estético causal para as escolhas interpretativas servem como motivos primários preponderantes para a origem da ação metodológica do 'cuidado de si'. Nesse sentido, arraigado à prática de interpretação musical, o 'cuidado de si' como teoria fundamental para o escopo proposto denota uma certa "tecnologia" para a atividade de subjetivação-objetivação, ou seja, da observação do sujeito como agente e objeto de seu próprio conhecimento. Com isso, a proposta apresentada sugere um formato longitudinal, propondo a inserção da prática musical como acionadora da razão reflexiva: toda a reflexão deve surgir do próprio ato performativo, da própria música, de maneira a envolver o sujeito em seu meio de atuação e meio de sociabilidade, e sua inclusão e fixação em um meio como nicho social, ou seja, a sua constituição como sujeito de si na performance musical. Em outras palavras, a atuação de um performer dentro de um círculo de performers.

0 interesse na trajetória empírica da "amostra", o registro dessa "amostra", e uma ascese com vista para um refinamento da ação músico-instrumental são os princípios motivadores nessa abordagem da filosofia do 'cuidado de si'. Para levar a efeito tais princípios, uma gama de ações podem valer-se como tal:

A manutenção de registros sobre atividades envolvidas na prática musical da obra envolvida representa o lugar de retorno do "eu" e de geração de reflexão. Nesses registros são válidos os seguintes procedimentos:

1. Condicionamento de um arquivo sobre aspectos históricos que envolvem a obra. Informações sobre o compositor e conhecimento de outros trabalhos teóricos sobre a obra;

2. Manutenção de um arquivo contendo ideias sobre a concepção artística da obra. Criação de imagens, metáforas e ideais estéticos;

3. Para a composição desses ideais estéticos, construir condições filosóficas para uma genealogia inversa da performance, a fim de ser possível exercer a escolha sobre qual o caminho a seguir no futuro;

4. A manutenção de um arquivo com gravações de outros intérpretes da obra selecionada. Em meu entendimento, a partir da literatura [Ver Gerling, (2000), Philip (2004) e Molina (2006), entre outros], gravações criam um tipo de tradição de performance, iniciando um primeiro corpo de interação e envolvimento social;

5. A variabilidade da escolha da origem de acordo com a conceituação dos próprios registros realizados: um movimento de descontinuidade condicionando a ação de produção da sua própria tradição;

6. Registro audiovisual da prática musical: a gravação dos vários recitais em que se incluiria a obra que se deseja fixar no repertório. Vários momentos de diver- 
sidades, de alteridade, de condicionalidade e de atitude sobre a própria obra;

7. Registro da preparação para os recitais. 0 registro de produtos da prática constituem atividade de regulação da prática, de autoavaliação e observação para projeções de ideias e imagens musicais a serem incorporadas para o momento da performance - como vários a priori;

8. Criação de um grupo virtual de cuidado da performance, mantendo contato individualmente e particularmente com cada integrante por meio de cartas. Nessa atividade, pode-se enviar uma cópia de momentos de registros de provas de performance para apreciação de um grupo de pianistas, com formação acadêmica. A comunicação com esse grupo pode dar-se por email, proporcionando assim um efetivo feedback e possibilidade de ampliação de visão de mundo acerca de sua própria performance, valorizando a ação do outro sobre sua própria atividade.

9. Retorno constante a esses procedimentos, de modo a tornar-se uma verdadeira prática. Constituindo um efetivo contexto de reflexão, sua própria autorreflexão.

\section{Considerações finais}

Todos esses procedimentos podem ser vistos como uma atividade de escrita de si. A escrita de si, como apresentado, conduz a um amadurecimento próprio do movimento de ascese que delineia o princípio do 'cuidado de si'. Suas pretensões aqui expostas são pertinentes e conduzidas ao próprio fazer musical pretendendo tornar tal prática como cerne e elemento de reflexão ativa para a pesquisa em práticas interpretativas sob um viés filosófico, evidentemente, mas este regido, iminentemente pela própria prática musical. A subjetividade do ato, e como articular-se mediante a necessidade de um constructo teórico, como sugere Santos (2002), leva a procurar por um delineamento metodológico mais eficiente e coerente. Com isso, as ideias de Foucault (2010) sobre o 'cuidado de si', oriundas do curso A Hermenêutica do Sujeito, pareceram muito aplicáveis. Oportunamente, Hara (2006) coloca o pensamento de Foucault como um aparelho de giro que se adapta a qualquer circunstância, de maneira que

Os possíveis usos da filosofia ou da "ação filosófica" de Foucault na atualidade são surpreendentes e múltiplos [...].

Tem-se a impressão forte de que neste agora, a figura [do performer sob o olhar de Foucault] é como aquele rosto desenhado na areia da praia"1. Transforma-se, desaparece e ressurge conforme a maré das interpretações. E o movimento é incessante e tem finalidades diferentes [...] (HARA, 2006, p. 198).

11 Em alusão ao final de As palavras e as coisas. Ver: Foucault, 2005, p. 422. 


\section{Referências}

$>$ ABBAGnANO, Nicola. Dicionário de Filosofia. 2š ed. São Paulo: Martins Fontes, 1998.

> AQUINO, Felipe A. Práticas Interpretativas e a Pesquisa em Música: dilemas e propostas. Opus 9 - Revista da Associação Nacional de Pesquisa e Pós-Graduação em Música / ANPPOM. Dezembro - 2003. Disponível em: 〈http://www.anppom. com.br/opus/opus9/opus9-8.pdf>. Acesso em 03/03/2011.

> BARRENECHEA, Lúcia. Pesquisa no Brasil: Balanço e Perspectivas. Opus 9 - Revista da Associação Nacional de Pesquisa e Pós-Graduação em Música / ANPPOM. Dezembro - 2003. Disponível em: http://www.anppom.com.br/opus/opus9/opus99.pdf. Acesso em 03/03/2011.

$>$ DERRIDA, Jacques. Força e significação. In: A Escritura e a Diferença. Tradução de Maria Beatriz Marques; Nizza da Silva, Pedro Leite Lopes e Pérola de Carvalho. 4š. Edição. São Paulo: Perspectiva, 2009. Capítulo 1, pp 1-41.

> FOUCAULT, Michel. Ditos e escritos: ética, sexualidade, política. Organização: Manoel Barros da Motta. Tradução: Elisa Monteiro, Inês Autran Dourado Barbos. 2. ed. Rio de Janeiro: Forense Universitária, 2010b. 1982). Tradução: Márcio Alves da Fonseca, Salma Tannus Muchail. 3š edição. São Paulo: WMF Martins Fontes, 2010.

As Palavras e as Coisas: uma arqueologia das ciências humanas. Tradução de António Ramos Rosa. Lisboa: Edições 70, 2005.

> GERLING, Fredi Vieira. Performance analysis and analysis for performance: a study of Villa-Lobos's Bachianas Brasileiras no. 2. Essay for Doctor of Musical Arts Degree (Tese de Doutorado), 2000. University of Iowa.

> HARA, Tony. Michel Foucault: um rosto desenhado na areia. VERVE: Revista Semestral do NU-SOL - Núcleo de Sociabilidade Libertária/ Programa de Estudos Pós-Graduados em Ciências Sociais, PUC-SP. n. 9 (maio 2006 -). São Paulo: 0 Programa, 2006.

> MOLINA (Jr), Sidney José. 0 violão na era do disco: interpretação e desleitura na arte de Julian Bream. Tese de Doutorado. Pontifícia Universidade Católica de São Paulo, São Paulo, 2006.

> MORIN, Edgar. A cabeça bem-feita: repensar a reforma, reformar o pensamento. Rio de Janeiro: Bertrand Brasil, 2003.

> PHILIP, Robert. Performing Music in the age of recording. New Haven $t$ London: Yale University Press, 2004.

> SANTOS, Boaventura de S. Introdução a uma Ciência Pós-Moderna. 6. ed. Porto: Afrontamento, 2002.

> VEYNE, Paul. Foucault: seu pensamento, sua pessoa. Tradução: Marcelo Jacques de Morais. Rio de Janeiro: Civilização Brasileira, 2011. 
> VIEIRA, Daniel. 'Boisinhos' e 'Lobosinhos' de Heitor Villa-Lobos: o cuidado de si no processo de performance como crítica para a constituição de um sujeito de atitude estética. Tese de Doutorado. Universidade Federal do Rio Grande do Sul, Porto Alegre, 2012.

> VIEIRA, Daniel. Do encantamento para a apropriação artística: experiência e performance musical, filosofia e hermenêutica, estética e ética. Revista do Conservatório de Música da UfPel. Pelotas, nć4, 2011. p. 194-217.

Daniel Vieira, ISEI zharbo@gmail.com 